\title{
Stimulus requirements for pregnancy initiation in the golden hamster (Mesocricetus auratus) change with time of mating during the receptive period
}

\author{
U. W. Huck, R. D. Lisk and C. Thierjung \\ Department of Biology, Princeton, New Jersey 08544, U.S.A.
}

\begin{abstract}
Summary. When maintained under a $14 \mathrm{~L}: 10 \mathrm{D}$ photoperiod, the duration of behavioural receptivity in female golden hamsters was about $18-21 \mathrm{~h}$ depending on age and/or parity. The effectiveness of mating stimuli in initiating pregnancy was shown to be a function of when in the receptive period (early, middle, late) that mating occurred. During the 9-h period before ovulation, 5 ejaculatory series were sufficient to produce a nearly $100 \%$ pregnancy rate and maximum litter size. During the ovulation period, however, high pregnancy rates were achieved only when mating continued to satiety (12-15 ejaculatory series plus 10-24 long intromissions). Late in the receptive period even mating to satiety failed to result in a pregnancy. In general, pregnancy rates were significantly higher for young virgin than for older multiparous females when mating occurred during or after the ovulation period. The reduced fecundity of females mating during or after ovulation was due to insufficient vaginocervical stimulation to induce functional luteal activity and not to lack of spermatozoa. Females mating late in the receptive period did not show a cessation of oestrous cycles which characteristically follows the induction of a luteal phase. Greater amounts of vaginocervical stimulation during this time increased the number of females which delivered litters but had no significant effect on litter size. These results suggest that levels of male copulatory behaviour considered 'excessive' when mating occurs early in the receptive period are essential for pregnancy initiation when mating occurs later.
\end{abstract}

\section{Introduction}

The amount of copulatory stimulation necessary to initiate pregnancy not only varies widely between species but also within a species, depending on an individual's age and previous reproductive history (Dewsbury, 1978). Specifically, copulatory stimuli necessary for pregnancy initiation have been shown to vary significantly depending on whether the female is in cyclic or postpartum oestrus (rat: Davis \& Connor, 1980; prairie vole, deer mouse and white-footed mouse: Dewsbury, Evans \& Webster, 1979). Age and/or parity may also affect the stimulus requirements for pregnancy initiation (Davis, Gray \& Dewsbury, 1977; Dewsbury, 1979). In the golden hamster, virgin females required significantly less copulatory stimulation than did multiparous females to induce pregnancy and maximize litter size (Huck \& Lisk, 1985b). This recognition of the changing stimulus requirements for initiation of pregnancy over the life history of an individual may provide a functional explanation for the large number of ejaculatory series shown by males of many of these species (e.g. rat: Davis et al., 1977; Adler, 1978; golden hamster: Huck \& Lisk, 1985b). Multiple ejaculations with the same female may not be wasted reproductive potential as some have maintained (e.g. Zucker \& Wade, 1968) but an essential stimulus for transcervical sperm transport and/or induction of functional luteal activity (rats: Wilson, Adler \& LeBoeuf, 1965; Chester \& Zucker, 1970; Matthews \& Adler, 1977; voles: Davis, Gray, Zerylnick \& Dewsbury, 1974; Milligan, 1975; Gray, Davis, Kenney \& Dewsbury, 1976; golden hamsters: Lanier, Estep \& Dewsbury, 1975; Huck 
\& Lisk, 1985b; Israeli gerbils: Dewsbury, Estep \& Oglesby, 1978; Peromyscus spp.: Dewsbury \& Lanier, 1976).

When maintained under a photoperiod of $14 \mathrm{~h}$ light:10 h dark (14L:10D), female golden hamsters are sexually receptive from the afternoon of pro-oestrus to about $12: 00 \mathrm{~h}$ on the following day (oestrus) (Reuter, Ciaccio \& Lisk, 1970; Ciaccio \& Lisk, 1971). In this species, ovulation is fixed in relation to the light-dark cycle (Alleva, Waleski, Alleva \& Umberger, 1968) and occurs between $01: 00$ and $04: 00 \mathrm{~h}$ on the day of oestrus. The female is therefore receptive for $9-11 \mathrm{~h}$ preceding ovulation and for another $8-10 \mathrm{~h}$ after ovulation. Although the reason for such an extended period of receptivity is unknown, it is of interest to determine the effectiveness of mating stimuli in the initiation of pregnancy and in litter size as a function of when in the receptive period (early, middle, late) that mating occurs. In our previous work (Huck \& Lisk, 1985b) we showed that the stimulus requirements necessary to initiate pregnancy varied significantly between virgin and multiparous females, and so animals of both types were used in the following experiments.

Copulatory behaviour in the golden hamster consists of mounts, short intromissions (2-3 sec vaginal penetration) and ejaculations. These are organized into discrete series with each series terminating in an ejaculation (Bunnell, Boland \& Dewsbury, 1977; Huck \& Lisk, 1985a). After 12-14 ejaculatory series, males show a modified copulatory pattern consisting of long intromissions lasting 10-30 sec during which the male shows intravaginal thrusting but no sperm transfer (Bunnell et al., 1977; Huck \& Lisk, 1985b).

In Exp. 1 we established a population graph for the onset and termination of receptivity in unmated individuals under the conditions of our study. In Exp. 2 we tested the fecundity of young virgin and older multiparous females as a function of the time of mating during the receptive period and number of ejaculatory series received. In Exp. 3 we examined whether the decreased fecundity of females mated late in the receptive period was due to an insufficiency in the number of spermatozoa received or in the amount of vaginocervical stimulation.

\section{General methods}

Animals and husbandry. The study involved 884 virgins, 830 multiparous females, and 187 stud males. All were laboratory-born descendants of the LVG strain obtained from Charles River, Inc., 251 Ballardvale Street, Wilmington, Mass. 01887, U.S.A. At testing the virgins were 95-146 days of age (mean 128.1 days) and weighed 106-143 g (mean $129 \cdot 7 \mathrm{~g}$ ). The multiparous females were 189-239 days of age (mean 206.7 days) and weighed 125-170 g (mean $153.7 \mathrm{~g}$ ). Each had successfully reared two litters before the study. The stud males were 168-241 days of age (mean 193.1 days) and weighed 121-158 g (mean 134.1 g). Each had sired two or more previous litters and was rested (no sexual contact) for at least 2 weeks between tests. At testing all females were in natural oestrus as determined by extravaginal examination (Orsini, 1961) and each was used only once.

All animals were maintained in windowless, air conditioned rooms on a $14 \mathrm{~h}$ light:10 h dark photoperiod (lights off at 19:00 h). Each was individually housed in a $35 \times 20 \times 17.5 \mathrm{~cm}$ rack-mounted cage provided with commercial laboratory chow and water ad libitum. After mating, females were transferred to plastic breeding boxes with wood shavings for bedding.

Apparatus. All receptivity and mating tests were conducted in a semicircular Plexiglas arena with a diameter of $35 \mathrm{~cm}$.

\section{Detailed methods and results}

\section{Experiment 1: receptivity}

Previous estimates of the duration of receptivity in the golden hamster range from 12 to $20 \mathrm{~h}$ (Frank \& Fraps, 1945; Kent, 1968; Ciaccio \& Lisk, 1971). Since the data reported from these 
different laboratories show considerable variance in the duration of receptivity, it was first necessary to determine for our conditions of animal maintenance the duration of the receptive period. In previous studies the parity of the animals had not been indicated and since this might be a confounding factor, we have determined the duration of receptivity for both virgin and for older multiparous females.

Procedure. Beginning at 13:00 h on the day of pro-oestrus, females were removed from their home cages and placed into the Plexiglas arena containing an habituated (at least 5 min) stud male. Females were scored as 'receptive' if they assumed the lordotic posture within $15 \mathrm{~min}$ or 'nonreceptive' if they failed to show lordosis during that time or if they attacked the male. All females were tested each hour until 17:00 h the next day (oestrus). Females were not exposed to the same male twice. A total of 25 virgin and 25 multiparous females arbitrarily selected from our laboratory stock (see above) were used. Intromissions were prevented by removing the male whenever mounting occurred while the female was displaying lordosis.

Results. The onset and duration of behavioural oestrus in virgin and multiparous females are shown in Fig. 1. The mean duration of oestrus was significantly longer for virgins than for older multiparous females $(20 \mathrm{~h} 34 \mathrm{~min} v s 18 \mathrm{~h} 17 \mathrm{~min} ; t=18 \cdot 72, P<0.001)$. This effect was due both to an earlier onset and later termination in receptivity among the virgin females. Receptivity began, on average, at 16:24 $\mathrm{h}$ amongst virgin and 17:34 h amongst older multiparous females. Virgin females were last receptive at $11: 58 \mathrm{~h}$ of oestrus while multiparous females were last receptive at $10: 50 \mathrm{~h}$.

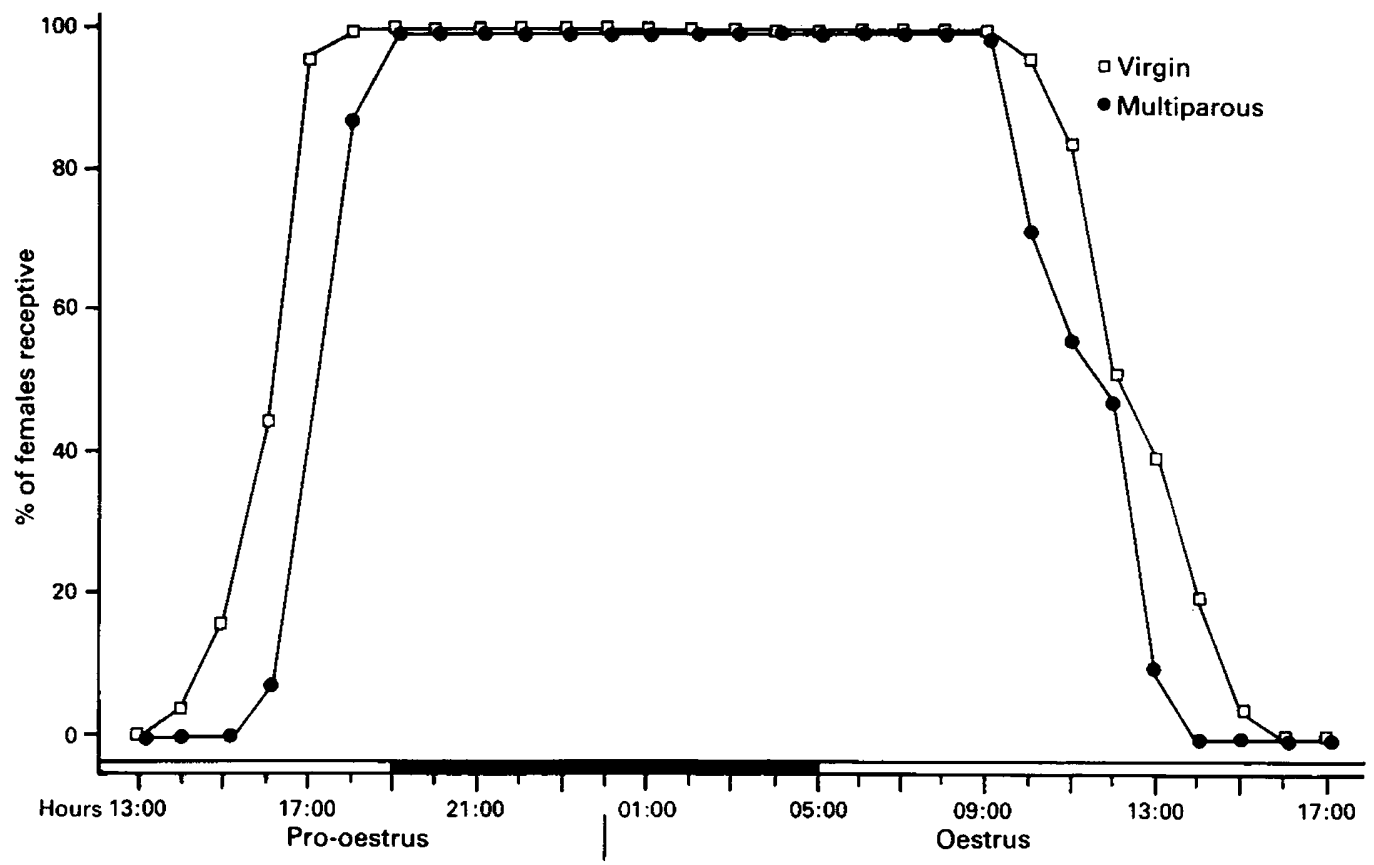

Fig. 1. Duration of behavioural oestrus in virgin $(N=25)$ and multiparous $(N=25)$ golden hamsters as indicated by the proportion of females that assumed the lordosis posture in the presence of a stud male.

\section{Experiment 2: pregnancy success as a function of time of mating}

Huck \& Lisk (1985b) have demonstrated that virgin female golden hamsters require significantly less copulatory stimuli than do older multiparous females to induce pregnancy and 

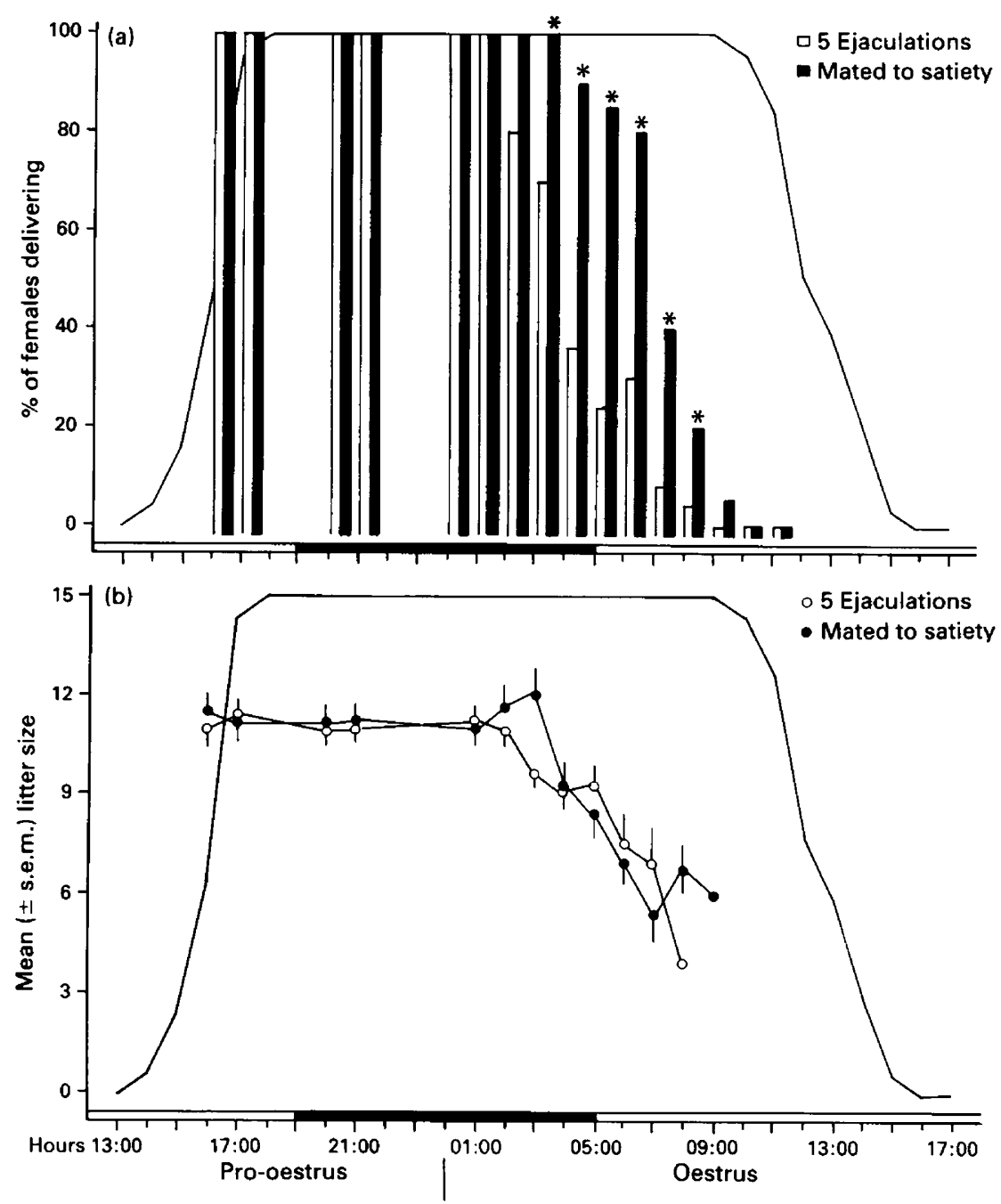

Fig. 2. Pregnancy rates (a) and mean litter sizes (b) for virgin females mated to 5 ejaculatory series (open bar) or to satiety (solid bar) at various times during the receptive period. Asterisks indicate significant differences $\left(\chi^{2}\right.$ tests corrected for continuity, $\left.P<0.05\right)$ in the proportion of females delivering litters as a function of the amount of copulatory stimulation received; $\mathrm{N}=20-35$ per group). Duration of receptivity curve (from Fig. 1) has been superimposed.

maximize litter size. Lanier et al. (1975) reported that multiparous females of the same strain required significantly more copulatory stimulation for pregnancy initiation than reported by us. One difference in the test protocols is that Lanier $e$ t al. (1975) mated their animals 4-6 h after lights out while we mated ours, on average, $3 \mathrm{~h}$ earlier. This suggests that the sensitivity to mating stimuli is changing over the duration of the receptive period. We therefore tested the effectiveness of 5 ejaculatory series versus mating to satiety (12-14 ejaculatory series plus long intromissions) for virgin and older multiparous females when mating was initiated at specific hourly intervals between 16:00 $\mathrm{h}$ on the day of pro-oestrus and 11:00 h on the day of oestrus. Five ejaculatory series were used since this level of copulatory stimulation was sufficient to effect a $100 \%$ pregnancy rate in females mated early during the receptive period (Huck \& Lisk, 1985b). 

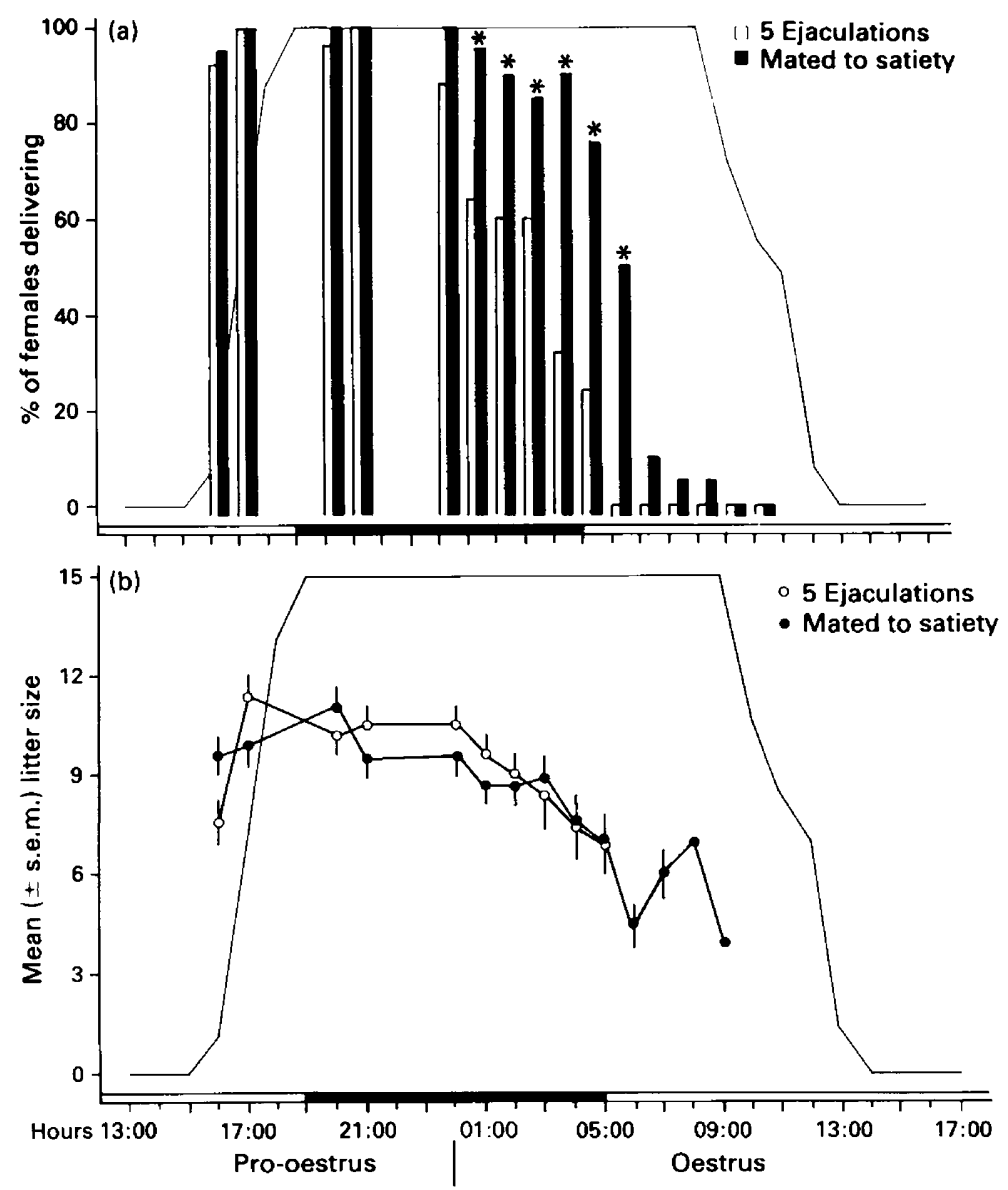

Fig. 3. Pregnancy rates (a) and mean litter sizes (b) for multiparous females mated to 5 ejaculatory series (open bar) or to satiety (solid bar) at various times during the receptive period. Asterisks indicate significant differences $\left(\chi^{2}\right.$ tests corrected for continuity, $\left.P<0.05\right)$ in the proportion of females delivering litters as a function of the amount of copulatory stimulation received; $\mathrm{N}=20-25$ per group). Duration of receptivity curve (from Fig. 1) has been superimposed.

Procedure. Beginning at 16:00 h on the day of pro-oestrus and continuing until 11:00 $\mathrm{h}$ of oestrus (see Fig. 2), females were placed into a Plexiglas arena containing an habituated stud male. Females of one group were allowed to mate for 5 ejaculatory series, while females of a second group remained paired until a satiety criterion of $15 \mathrm{~min}$ without copulation was reached or until she attacked the male. Mated females were then placed into plastic breeding boxes and their oestrous condition checked daily beginning 4 days later. A total of 759 virgin (20-35 at each level of stimulation and testing time) and 705 multiparous females (20-25 per group) were used.

Results. The percentage of virgin and older multiparous females that delivered litters is summarized in Figs 2(a) and 3(a), respectively. Pregnancy rates for both types of females and for both levels of copulatory stimulation were at or near $100 \%$ when matings occurred early during the receptive period (i.e. before $01: 00 \mathrm{~h}$ of oestrus). The percentage of females delivering as a result of matings later in the receptive period declined in all experimental groups, but the specific timing of the decline was a function of female parity (or age) as well as of the amount of copulatory stimulation received. 
Table 1. Pregnancy rates of virgin and multiparous hamsters mated at various times during the receptive period

\begin{tabular}{|c|c|c|c|c|c|}
\hline \multirow{2}{*}{$\begin{array}{l}\text { Time of } \\
\text { mating } \\
\text { (h) }\end{array}$} & \multicolumn{2}{|c|}{ Virgin } & \multicolumn{2}{|c|}{ Multiparous } & \multirow[b]{2}{*}{$\chi^{2}$} \\
\hline & $\begin{array}{l}\text { No. } \\
\text { tested }\end{array}$ & $\begin{array}{c}\text { No. (\%) } \\
\text { delivering }\end{array}$ & $\begin{array}{l}\text { No. } \\
\text { tested }\end{array}$ & $\begin{array}{c}\text { No. (\%) } \\
\text { delivering }\end{array}$ & \\
\hline \multicolumn{6}{|c|}{5 Ejaculations } \\
\hline $\begin{array}{l}16: 00-24: 00 \\
01: 00-06: 00 \\
07: 00-11: 00\end{array}$ & $\begin{array}{l}148 \\
135 \\
135\end{array}$ & $\begin{array}{r}148(100) \\
85 \quad(63) \\
12 \quad(8)\end{array}$ & $\begin{array}{l}120 \\
125 \\
140\end{array}$ & $\begin{array}{r}114(95) \\
57(46) \\
0(0)\end{array}$ & $\begin{array}{l}5 \cdot 45^{*} \\
7 \cdot 89^{* *} \\
9 \cdot 38^{* *}\end{array}$ \\
\hline \multicolumn{6}{|l|}{ Satiety } \\
\hline $\begin{array}{l}16: 00-24: 00 \\
01: 00-06: 00 \\
07: 00-11: 00\end{array}$ & $\begin{array}{l}101 \\
100 \\
120\end{array}$ & $\begin{array}{r}101(100) \\
95(95) \\
29(24)\end{array}$ & $\begin{array}{l}100 \\
100 \\
120\end{array}$ & $\begin{array}{l}99(99) \\
87(87) \\
14(12)\end{array}$ & $\begin{array}{l}0 \cdot 00 \\
3 \cdot 91^{*} \\
6 \cdot 37^{*}\end{array}$ \\
\hline
\end{tabular}

For virgins mated between 03:00 and 08:00 $\mathrm{h}$ and for older multiparous females mated between $01: 00$ and $06: 00 \mathrm{~h}$, pregnancy rates were significantly higher amongst animals mated to satiety than amongst those receiving only 5 ejaculatory series. However, regardless of the amount of stimulation received, none of the virgin and multiparous females mating at 10:00 or 11:00 h delivered litters. Except for a multiparous female mated to satiety at $16: 00 \mathrm{~h}$ of pro-oestrus and a virgin mated to 5 ejaculatory series at $02: 00 \mathrm{~h}$ of oestrus, all the animals that failed to deliver litters continued to show regular 4-day oestrous cycles following mating.

For females mated after $24: 00 \mathrm{~h}$, pregnancy rates were significantly higher for virgin than for older multiparous females at both levels of copulatory stimulation (Table 1). Pregnancy rates for virgin females mated early during their receptive period (i.e. 16:00-24:00 h) were also somewhat higher than those of their multiparous counterparts but only amongst groups in which copulation was restricted to 5 ejaculatory series.

Mean litter sizes for virgin and older multiparous females are summarized in Figs 2(b) and 3(b), respectively. For both types of female, changes in litter size paralleled changes in pregnancy rates. Repeated measures ANOVA tests indicated that litter size varied significantly as a function of time of mating in both virgin $(F=139 \cdot 18, P<0.001)$ and multiparous females $(F=156.82, P<0.001)$. With the exception of multiparous females mated to 5 ejaculatory series at $16: 00 \mathrm{~h}$, mean litter sizes for both types of female and at both levels of copulatory stimulation were relatively high when mating occurred early during the receptive period and then declined sharply thereafter. Overall, virgin females tended to produce larger litters than did their multiparous counterparts $(t=8 \cdot 74$, $P<0 \cdot 001$ ). However, there was no significant effect due to amount of copulatory stimulation received $(t=1 \cdot 47, \mathrm{NS})$.

Experiment 3: a test of the relative efficacy of sperm number versus copulatory stimuli in facilitating pregnancy initiation late in the receptive period

The increased fecundity of females mating to satiety at $01: 00 \mathrm{~h}$ or later vis-a-vis those receiving 5 ejaculatory series in Exp. 2 could be a consequence of the larger numbers of spermatozoa received or of the extra vaginocervical stimulation. Pregnancy rates were therefore compared in groups of females which varied systematically in the number of ejaculations and intromissions received. This experiment was conducted at two times (04:00 and 06:00 h) when mating to satiety significantly increased fecundity (see above).

Procedure. An additional 100 virgin and 100 multiparous females were assigned to one of 8 
experimental groups (see Figs 4a and 4b). About half the females were tested at 04:00 h of oestrus while the other half were tested at $06: 00 \mathrm{~h}$. Two levels of copulatory stimuli were used. Half of the females received 5 ejaculatory series from a stud male (using the same procedures described in the previous experiment) followed immediately by a second male which provided 12-27 long intromissions ( $5 \mathrm{Ej}+\mathrm{LI}$ group). The latter effect was achieved by allowing a male to ejaculate to satiety with two consecutive females immediately before use as a stimulus male in the present experiment. Although male hamsters occasionally engage in ejaculations between bouts of long intromissions (Bunnell et al., 1977), this occurred in only 4 cases in the present experiment and these females were excluded from further consideration. The females of the other group were allowed to mate with a stud male until the first long intromission was observed. This usually occurred after 12-15 ejaculatory series (13 Ej group). The male was then removed.

An additional 8 treatment groups from the previous experiment were included for statistical comparisons. These consisted of virgin and multiparous females mated at 04:00 or 06:00 $\mathrm{h}$ that had received 5 ejaculatory series from a rested male $(5 \mathrm{Ej}$ group) and those that had been allowed to mate to satiety (13 Ej $+\mathrm{LI}$ group). Females in the latter group had received 12-15 ejaculatory series plus 10-24 long intromissions.

Results. Percentages of females delivering litters as well as mean litter sizes are summarized in Figs 4(a) and 4(b) for virgin and multiparous females, respectively. For females of both types mated at 04:00 and 06:00 h, pregnancy rates were significantly lower for subjects in the $5 \mathrm{Ej}$ group than for

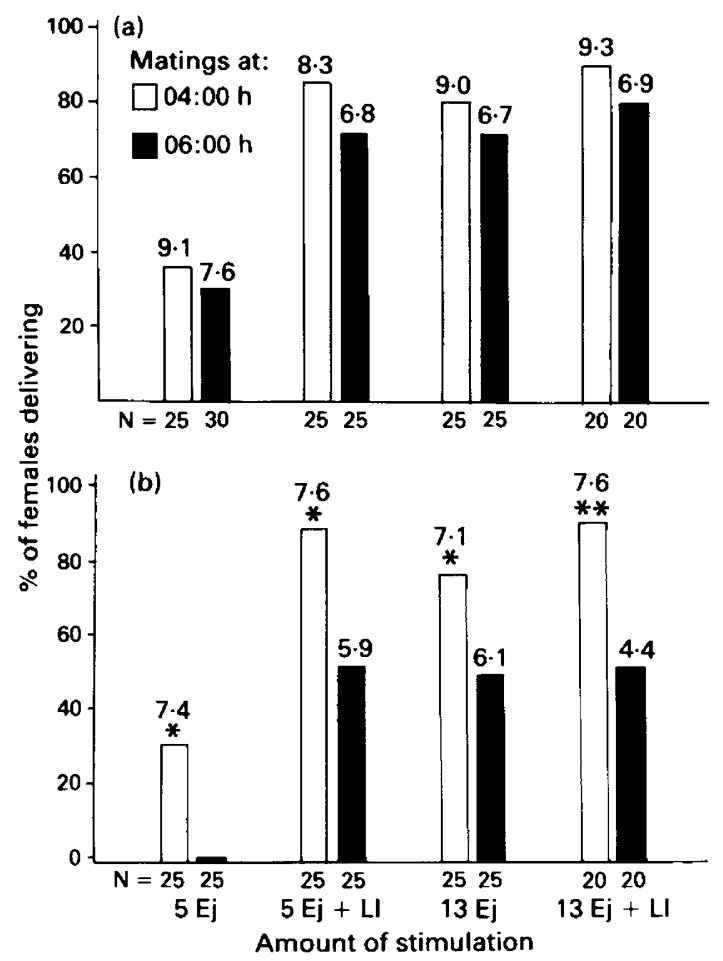

Fig. 4. Pregnancy rates and mean litter sizes for virgin (a) and multiparous (b) females mated at 04:00 or $06: 00 \mathrm{~h}$. Numbers above bars indicate mean litter size while the numbers below the bars indicate the total number of females tested with 5 or 13 ejaculatory series (Ej) with or without long intromissions (LI). Asterisks indicate significant differences in the proportion of females delivering litters as a function of time of mating (04:00 vs 06:00 h; $\chi^{2}$ tests corrected or continuity, $\left.{ }^{*} P<0 \cdot 05 ;{ }^{*} P<0 \cdot 01\right)$. 
females in the other 3 groups ( $\chi^{2}$ tests with Yates correction factor, $P<0.05$ ) which did not differ significantly from one another. Pregnancy rates for multiparous females were consistently higher when matings occurred at 04:00 than when they occurred at 06:00 h. This effect was less pronounced amongst the virgin females. Except for a multiparous female in the $5 \mathrm{EJ}$ group mated at 04:00 $\mathrm{h}$ and one virgin in the $5 \mathrm{EJ}+\mathrm{LI}$ group also mated at 04:00 $\mathrm{h}$, all the animals that failed to deliver litters continued to show regular oestrous cycles.

Results of a 3-way ANOVA indicated that litter size was affected by time of mating and female parity (or age). Litters were larger for virgin than for older multiparous females $(F=16 \cdot 67$; $P<0.001)$ and for females mated at $04: 00 \mathrm{~h}(\mathrm{~F}=47.17, P<0.001)$, but there was no significant effect due to the amount of copulatory stimulation received $(\mathrm{F}=1 \cdot 05, \mathrm{NS})$.

\section{Discussion}

The duration of the receptive period in unmated female hamsters was significantly longer for virgin than for multiparous females. Since there was an average age difference of 11 weeks between these groups, it is possible that the duration of receptivity in unmated females varies more as a function of age than of parity. The shortened receptive period of older multiparous females may be adaptive in view of their reduced pregnancy rates when mated late in the receptive period and the costs associated with infertile mating (see Adler, 1978).

In a previous study from this laboratory (Reuter et al., 1970), we showed that, for 3-month-old virgin hamsters maintained on the same 14L:10D photoperiod employed in the present study, ovulation occurred in all members of the group between 01:00 and 04:00 $\mathrm{h}$ on the morning of oestrus. It was further shown that mating stimulation did not affect the time of ovulation. The results of the present study, therefore, indicate that if mating occurs before ovulation (i.e. $16: 00-24: 00 \mathrm{~h}$ of pro-oestrus), 5 ejaculatory series were sufficient to produce a pregnancy rate of nearly $100 \%$ and maximum litter size. In contrast, during the ovulation period (01:00-04:00 h), high pregnancy rates were achieved only when mating was continued to satiety (Figs $2 \mathrm{a}$ and $3 \mathrm{a}$ ). In Exp. 3 we showed that the reduced fecundity of females mated during the ovulatory period $(04: 00 \mathrm{~h})$ or shortly thereafter $(06: 00 \mathrm{~h})$ was due to insufficient vaginocervical stimulation and not to a lack of spermatozoa. Late in the receptive period (i.e. after 10:00 h of oestrus) even mating to satiety failed to result in a pregnancy for any female, virgin or multiparous.

In the rat, sperm transport, initiation of the luteal phase and the number of implantation sites have all been shown to be dependent upon the amount of copulatory stimulation the female receives (e.g. Adler, 1969; Matthews \& Adler, 1977; Davis et al., 1977). In the golden hamster, however, the amount of copulatory stimulation received has been shown to affect only the induction of the luteal phase (Lanier et al., 1975; Huck \& Lisk, 1985b) and not sperm transport or the number of implantation sites (Lanier et al., 1975; Lisk, 1985). In the present study the small number of pseudopregnancies among females that did not deliver litters suggests that pregnancy failure was due to a failure of the neuroendocrine reflex rather than to problems associated with sperm transport. It appears, therefore, that in the golden hamster the amount of vaginocervical stimulation necessary to interrupt the oestrous cycle and initiate pregnancy increased over the period of receptivity.

While an increased amount of vaginocervical stimulation was highly effective in increasing the percentage of females delivering litters, it had no significant effect on litter size (Figs $2 \mathrm{~b}$ and $3 \mathrm{~b}$ ). In fact, mean litter size decreased significantly for females mated during or after ovulation. Since copulatory stimuli in the hamster have been shown to have no effect on the number of ova shed (Reuter et al., 1970), one must look elsewhere for an explanation for this effect. One possibility relates to the capacitation process and the relatively short fertilizable life-span of golden hamster ova. In mammals, spermatozoa are unable to fertilize ova until they have undergone complex physiological changes (i.e. capacitation) in the female reproductive tract. This process requires 
about $3 \mathrm{~h}$ in the golden hamster (Yanagimachi \& Chang, 1964; Yanagimachi, 1969). With regard to their fertilizable life-span, $86 \%$ of golden hamster ova were fertilizable $3 \mathrm{~h}$ after ovulation, less than half remained fertilizable $6 \mathrm{~h}$ after ovulation, and only $9 \%$ were fertilizable at $9 \mathrm{~h}$ (Ward, 1946; Yanagimachi \& Chang, 1964). In the present study, the ova of females mated at 04:00 h would not be fertilized until 3-6 $\mathrm{h}$ after ovulation and those of females mated at 10:00 $\mathrm{h}$ would not be fertilized until $9-12 \mathrm{~h}$ after ovulation. The decline in mean litter size in matings during and after the ovulation period may therefore be due to the fragility of the ovulated ova.

Nearly all of the females mated after 09:00 h continued to display normal 4-day oestrous cycles. In view of the foregoing discussion of the short fertilizable life-span of hamster ova, this finding suggests that the decreased sensitivity of the neuroendocrine response to vaginocervical stimulation late in the receptive period could safeguard the female against the initiation of a pseudopregnancy (or small litter) at a time when few if any of her ova are fertilizable. Induction of a pseudopregnancy would be particularly disadvantageous to a short-lived rodent such as the hamster (Conaway, 1971).

It is not clear why female golden hamsters continued to mate even when pregnancy is no longer possible (i.e. after 09:00 h). However, since mating to satiety with a single male early during the receptive period reduces the duration of behavioural oestrus from $18 \mathrm{~h}$ to $11 \mathrm{~h}$ in multiparous females (Huck \& Lisk, 1985c), it is possible that the above phenomenon is a laboratory artefact and rarely occurs under natural conditions where potential mates are, presumably, available earlier during the receptive period.

It is not known whether the changes in stimulus requirements for pregnancy initiation observed in the golden hamster occur in other species. In rats, Chester \& Zucker (1970) found that when ejaculations occurred on the second intromission, all of 5 females mated late in the receptive period (i.e. after $22: 00 \mathrm{~h}$ ) became pregnant compared to only one of 6 animals mated before 22:00 h. (There was no effect when ejaculations occurred on the first intromission, however.) They suggested that this effect was due either to enhanced sperm transport (resulting from increased cervical relaxation) late in heat or to the decreased time interval between ejaculation and fertilization in the group mating later in the receptive period. However, since in their study all subjects were treated with $10 \mathrm{mg}$ progesterone on the morning after mating (which induced pseudopregnancy in all animals), any effect of time of mating on initiation of the neuroendocrine reflex was indiscernible. Clearly, additional studies on the type reported in the present paper are required to determine the generality of the observed effects.

The observed changes in stimulation requirements for pregnancy initiation during the female's receptive period reported here have important implications for the interpretation of patterns of male copulatory behaviour. For example, several workers have commented on the seemingly 'excessive' levels of copulatory behaviour in male rodents (reviewed by Dewsbury, 1981). In fact, Zucker \& Wade (1968) suggested that the multiple ejaculations shown by rats and hamsters are wasted activity or an artefact of domestication or laboratory testing. However, previously it was shown that multiple ejaculations by male hamsters may provide protection against sperm displacement as a result of matings with subsequent males (Oglesby, Lanier \& Dewsbury, 1981; Huck, Quinn \& Lisk, 1985). The results of the present study further suggest that levels of copulatory stimuli considered 'excessive' when delivered early during the female's receptive period may be essential for pregnancy initiation when mating occurs later.

There has also been considerable debate regarding the functional significance of the long intromission pattern of the male golden hamster (e.g. Bunnell et al., 1977). Huck \& Lisk (1985a) showed that, when mated daily, male hamsters produced an average of 4 ejaculations per day for 11 consecutive days and nearly all these ejaculations were followed by 10 or more long intromissions. The results of the present study suggest that, had those matings occurred late in the female's receptive period, long intromissions would have significantly increased the percentage of females that subsequently delivered litters.

This work was supported by Grant BNS-8300892 from the National Science Foundation. 


\section{References}

Adler, N.T. (1969) Effects of the male's copulatory behavior on successful pregnancy of the female rat. $J$. comp. Physiol. Psych. 69, 613-622.

Adler, N.T. (1978) On the mechanisms of sexual behavior and their evolutionary constraints. In Biological Determinants of Sexual Behavior, pp. 115-160. Ed. J. B. Hutchinson. J. Wiley, New York.

Alleva, J.J., Waleski, M.U., Alleva, F.R. \& Umberger, E.J. (1968) Synchronizing effect of photoperiodicity on ovulation in hamsters. Endocrinology 82, 1227-1235.

Bunnell, B.N., Boland, B.D. \& Dewsbury, D.A. (1977) Copulatory behavior of golden hamsters (Mesocricetus auratus). Behaviour 61, 180-206.

Chester, R.V. \& Zucker, I. (1970) Influence of male copulatory behavior on sperm transport, pregnancy and pseudopregnancy in female rats. $J$. comp. Physiol. Psych. 91, 281-289.

Ciaccio, L.A. \& Lisk, R.D. (1971) Hormonal control of cyclic estrus in the female hamster. Am. J. Physiol. 221, 936-942.

Conaway, C.H. (1971) Ecological adaptation and mammalian reproduction. Biol. Reprod. 4, 239-247.

Davis, H.N., Jr \& Connor, J.R., Jr (1980) Male modulation of female reproductive physiology in Norway rats: effects of mating during postpartum estrus. Behav. Neural Biol. 29, 128-131.

Davis, H.N., Jr, Gray, G.D. \& Dewsbury, D.A. (1977) Maternal age and male behavior in relation to successful reproduction by female rats (Rattus norvegicus). J. comp. Physiol. Psych. 91, 281-289.

Davis, H.N., Jr, Gray, G.D., Zerylnick, M. \& Dewsbury, D.A. (1974) Ovulation and implantation in montane voles (Microtus montanus) as a function of varying amounts of copulatory stimulation. Horm. Behav. 5, 383-388.

Dewsbury, D.A. (1978) The comparative method in studies of reproductive behavior. In Sex and Behavior, pp. 83-112. Eds T. E. McGill, D. A. Dewsbury \& B. D. Sachs. Plenum Press, New York.

Dewsbury, D.A. (1979) Copulatory behavior of deer mice (Peromyscus maniculatus). III. Effects on pregnancy initiation. J. comp. Physiol. Psych. 93, 178-188.

Dewsbury, D.A. (1981) On the function of the multiple-intromission, multiple-ejaculation copulatory patterns of rodents. Bull. Psychonomic. Soc. 18, 221-223.

Dewsbury, D.A. \& Lanier, D.L. (1976) Effects of variations in copulatory behavior on pregnancy in two species of Peromyscus. Physiol. Behav. 17, 921-924.

Dewsbury, D.A., Estep, D.Q. \& Oglesby, J. (1978) Copulatory behavior and the initiation of pregnancy in Israeli gerbils (Meriones tristrami). Biol. Behav. 3, 243-257.

Dewsbury, D.A., Evans, R.L. \& Webster, D.G. (1979) Pregnancy initiation in postpartum estrus in three species of Muroid rodents. Horm. Behav. 13, 1-8.

Frank, A.H. \& Fraps, R.M. (1945) Induction of estrus in the ovariectomized golden hamster. Endocrinology 37, 357-361.

Gray, G.D., Davis, H.N., Kenney, A. McM. \& Dewsbury, D.A. (1976) Effect of mating on plasma levels of LH and progesterone in montane voles (Microtus montanus). J. Reprod. Fert. 47, 89-91.
Huck, U.W. \& Lisk, R.D. (1985a) Determinants of mating success in the golden hamster (Mesocricetus auratus). I. Male capacity. J. comp. Psychol. 99, 98-107.

Huck, U.W. \& Lisk, R.D. (1985b) Determinants of mating success in the golden hamster (Mesocricetus auratus). II. Pregnancy initiation. J. comp. Psychol. 99, 231-239.

Huck, U.W. \& Lisk, R.D. (1985c) Mating-inducted inhibition of receptivity in the female golden hamster. I. Short-term and long-term effects. Behav. Neur. Biol. (in press).

Huck, U.W., Quinn, R.P. \& Lisk, R.D. (1985) Determinants of mating success in the golden hamster (Mesocricetus auratus). IV. Sperm competition. Behav. Ecol. Sociobiol. 17, 239-252.

Kent, G.C., Jr (1968) Physiology of reproduction. In The Golden Hamster, pp. 119-138. Eds R. A. Hoffman, P. F. Robinson \& H. Magalhaes. Iowa State University Press, Ames

Lanier, D.L., Estep, D.Q. \& Dewsbury, D.A. (1975) Copulatory behavior of golden hamsters: effects on pregnancy. Physiol. Behav. 1, 209-212.

Lisk, R.D. (1985) The regulation of sexual 'heat'. In The Hamster Reproduction and Behavior, pp. 425-466. Ed. H. F. Siegel. Plenum Press, New York.

Matthews, M. \& Adler, N.T. (1977) Facilitative and inhibitory influences of reproductive behavior on sperm transport in rats. J. comp. Physiol. Psych. 91, $727-741$.

Milligan, S.R. (1975) Mating, ovulation and corpus luteum function in the vole, Microtus agrestis. J. Reprod. Fert. 42, 35-44.

Oglesby, J.M., Lanier, D.L. \& Dewsbury, D.A. (1981) The role of prolonged copulatory behavior in male Syrian golden hamsters (Mesocricetus auratus) in a competitive mating situation. Behav. Ecol. Sociobiol. $8,47-54$.

Orsini, M.W. (1961) The external vaginal phenomena characterizing the stages of the estrous cycle, pregnancy, pseudopregnancy, lactation, and the anestrous hamster, Mesocricetus auratus. Proc. Anim. Care Panel 11, 193-206.

Reuter, L.A., Ciaccio, L.A. \& Lisk, R.D. (1970) Progesterone: regulation of estrous cycle, ovulation and estrous behavior in the golden hamster. Endocrinology 86, 1287-1297.

Ward, W.C. (1946) A study of the estrous cycle and the breeding of the golden hamster, Cricetus auratus. Anat. Rec. 94, 139-161.

Wilson, J.R., Adler, N.T. \& LeBoeuf, B. (1965) The effects of intromission frequency on successful pregnancy in the female rat. Proc. natn. Acad. Sci. U.S.A. 53, 1392-1395.

Yanagimachi, R. (1969) In vitro capacitation of hamster spermatozoa by follicular fluid. J. Reprod. Fert. 18, 275-286.

Yanagimachi, R. \& Chang, M.C. (1964) Fertilizable life of golden hamster ova and their morphological changes at the time of losing fertilizability. $J$. exp. Zool. 148, 185-197.

Zucker, I. \& Wade, G. (1968) Sexual preferences of male rats. J. comp. Physiol. Psychol. 66, 816-819.

Received 21 June 1985 